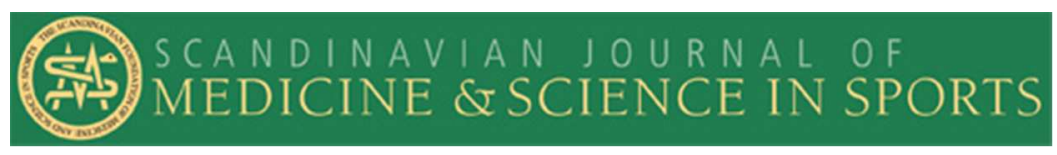

\title{
Chronic lactate supplementation does not improve blood buffering capacity and repeated high-intensity exercise
}

\begin{tabular}{|c|c|}
\hline Journal: & Scandinavian Journal of Medicine and Science in Sports \\
\hline Manuscript ID & SJMSS-O-325-16.R2 \\
\hline Manuscript Type: & Original Article \\
\hline Date Submitted by the Author: & $\mathrm{n} / \mathrm{a}$ \\
\hline Complete List of Authors: & $\begin{array}{l}\text { Oliveira, Luana; Universidade de Sao Paulo Escola de Educacao Fisica e } \\
\text { Esporte } \\
\text { de Salles Painelli, Vitor; Universidade de Sao Paulo Escola de Educacao } \\
\text { Fisica e Esporte } \\
\text { Nemezio, Kleiner; Universidade de Sao Paulo Escola de Educacao Fisica e } \\
\text { Esporte } \\
\text { Souza Gonçalves, Livia; Universidade de Sao Paulo Escola de Educacao } \\
\text { Fisica e Esporte } \\
\text { Yamaguchi, Guilherme; Universidade de Sao Paulo Escola de Educacao } \\
\text { Fisica e Esporte } \\
\text { Saunders, Bryan; Universidade de Sao Paulo Escola de Educacao Fisica e } \\
\text { Esporte } \\
\text { Gualano, Bruno; Universidade de Sao Paulo Escola de Educacao Fisica e } \\
\text { Esporte } \\
\text { Artioli, Guilherme; Universidade de Sao Paulo Escola de Educacao Fisica e } \\
\text { Esporte }\end{array}$ \\
\hline Keywords: & $\begin{array}{l}\text { buffering capacity, sodium bicarbonate, lactate, intermittent exercise, } \\
\text { upper-body Wingate, chronic supplementation }\end{array}$ \\
\hline
\end{tabular}

\section{SCHOLARONE}

Manuscripts 
1

2

3

4

5

6

7

8

9

10

11

12

13

14

15

16

17

18

19

20

21

22

23

24

25

26

27

28

29

30

31

32

33

34

35

36

37

38

39

40

41

42

43

44

45

46

47

48

49

50

51

52

53

54

55

56

57

58

59

60

1 Article Title: Chronic lactate supplementation does not improve blood buffering capacity and

2 repeated high-intensity exercise

3

4 Short Title: Calcium lactate does not affect performance

5

6 Submission type: Original Investigation

7

8 Authors:

9 Luana Farias de Oliveira ${ }^{1}$; Vitor de Salles Painelli ${ }^{1}$; Kleiner Nemezio ${ }^{1}$; Lívia Souza Gonçalves ${ }^{1}$;

10 Guilherme Yamaguchi $^{1}$; Bryan Saunders ${ }^{1}$; Bruno Gualano ${ }^{1}$; Guilherme Giannini Artioli ${ }^{1}$

12 Affiliations:

$13{ }^{1}$ Applied Physiology \& Nutrition Research Group, University of Sao Paulo, São Paulo, Brazil.

14

15 Corresponding author:

16 Guilherme G Artioli

17 Applied Physiology \& Nutrition Research Group

18 University of São Paulo

19 Av. Mello de Moraes 65

20 Butantã, 05508-030

21 Sao Paulo, SP, Brazil.

22 Phone: $+55113091-3096$

23 Fax: $+55113813-5921$

24 E-mail: artioli@usp.br

25 


\section{ABSTRACT:}

Purpose: Since there is conflicting data on the buffering and ergogenic properties of calcium lactate (CL), we investigated the effect of chronic CL supplementation on blood $\mathrm{pH}$, bicarbonate and high-intensity intermittent exercise performance. Sodium bicarbonate (SB) was used as a positive control. Methods: Eighteen athletes participated in this double-blind, placebo-controlled, crossover, fully counterbalanced study. All participants underwent three different treatments: placebo (PL), CL and SB. The dose was identical in all conditions: $500 \mathrm{mg} \cdot \mathrm{kg}^{-1} \mathrm{BM}$ divided into 4 daily individual doses of $125 \mathrm{mg} \cdot \mathrm{kg}^{-1} \mathrm{BM}$, for five consecutive days, followed by a 2-7 day washout period. On the fifth day of supplementation, individuals undertook four 30-s Wingate bouts for upper-body with 3-min recovery between bouts. Total mechanical work (TMW) for the overall protocol and for the initial $\left(1^{\text {st }}+2^{\text {nd }}\right)$ and final $\left(3^{\text {rd }}+4^{\text {th }}\right)$ bouts was determined at each session. Blood $\mathrm{pH}$, bicarbonate and lactate were determined at rest, immediately and $5 \mathrm{~min}$ after exercise. Results: CL supplementation did not affect performance ( $p>0.05$ for the overall TMW as well for initial and final bouts), nor did it affect blood bicarbonate and $\mathrm{pH}$ prior to exercise. SB supplementation improved performance by $2.9 \%$ for overall TMW $(\mathrm{p}=0.02)$ and $5.9 \%$ in the $3^{\text {rd }}+4^{\text {th }}$ bouts $(p=0.001)$. Compared to the control session, SB also promoted higher increases in blood bicarbonate than CL and PL $(+0.03 \pm 0.04 v s+0.009 \pm 0.02$ and $+0.01 \pm 0.03$, respectively). Conclusions: CL supplementation was not capable of enhancing high-intensity intermittent performance or changing extracellular buffering capacity challenging the notion that this dietary supplement is an effective buffering agent.

Keywords: buffering capacity, sodium bicarbonate, lactate, intermittent exercise, upper-body Wingate, chronic supplementation. 


\section{INTRODUCTION}

56

During high-intensity exercise, the rate of hydrogen ion $\left(\mathrm{H}^{+}\right)$production inside the skeletal muscle cells exceeds their neutralisation by the intracellular chemical buffers. Some of the $\mathrm{H}^{+}$are then exported to the blood via sodium $/ \mathrm{H}^{+}$and monocarboxilate transporters (MCT) (Juel 1996) where they are neutralised by the blood buffering systems, in particular, blood bicarbonate (Boning et al. 2007). Nonetheless, a rapid decline in both muscle and blood pH is observed during exercise despite the presence of several pH-regulating mechanisms (Costill et al. 1983). Intramuscular $\mathrm{H}^{+}$accumulation and the consequential muscle acidosis have long been considered important factors contributing to fatigue (Allen et al. 2008), as they may inhibit keyenzymes of energy metabolism (Sahlin et al. 1975). The $\mathrm{H}^{+}$accumulation in muscle may also interfere with the calcium transient (Donaldson et al. 1978) and impair the excitationcontraction coupling process (Fabiato \& Fabiato 1978). Supporting this notion, numerous human studies and meta-analyses have shown that increasing either intra- or extracellular buffering capacity via beta-alanine or sodium bicarbonate supplementation, can improve exercise capacity and performance, particularly in exercise where acidosis is limiting to performance (Carr et al. 2011; Lancha Junior et al. 2015; Peart et al. 2012) . Recently, a new nutritional strategy capable of increasing extracellular buffering capacity has gained some attention, namely acute ingestion of lactate (in the forms of polylactate, sodium lactate or calcium lactate) (Morris et al. 2011; Painelli et al. 2014).

Lactate supplementation has been postulated to increase extracellular buffering capacity. Upon ingestion, lactate is absorbed primarily in the jejunum through sodium-coupled intestinal lactate transporters ( either converted into glucose in the liver (Hostetler et al. 1969) or oxidised in skeletal muscle (Jacobs et al. 2013). Both processes result in a net utilisation of $\mathrm{H}^{+}$(Brooks 1986), which could spare blood bicarbonate, thereby increasing extracellular buffering capacity. Indeed, using a 7\% polylactate solution $(\sim 17.5 \mathrm{~g})$, Fahey et al. (1991) showed a 17\% increase in blood bicarbonate $\left(\sim 2.5\right.$ to $\left.3.0 \mathrm{mmol} \cdot \mathrm{l}^{-1} \mathrm{BM}\right)$ while Van Montfoort et al. (2004) similarly showed a significant 
$25 \%$ increase in blood bicarbonate $\left(\sim 6.2 \mathrm{mmol} \cdot 1^{-1}\right)$ with acute sodium lactate supplementation

84

85

86

87 (400 mg. $\mathrm{kg}^{-1} \mathrm{BM}$ ). Similarly, Morris, Shafer (2011) demonstrated that acute calcium lactate supplementation $\left(120 \mathrm{mg} \cdot \mathrm{kg}^{-1} \mathrm{BM}\right)$ induced a significant increase of $10 \%$ in blood bicarbonate $\left(\sim 2.7 \mathrm{mmol} \cdot 1^{-1}\right)$. Thus, it appears that lactate supplementation may increase blood buffering capacity which may improve high-intensity exercise limited by acidosis.

Van Montfoort, Van Dieren (2004) showed a small improvement in exercise tolerance in a continuous run-to-exhaustion protocol lasting $\sim 80 \mathrm{~s}$ while Morris, Shafer (2011) showed that acute lactate ingestion improved exercise performance by $17 \%$ in a supra-maximal exercise tolerance test following four repeated maximal exercise bouts. In contrast to these findings, an investigation from our group did not show any ergogenic effect of acute lactate ingestion on repeated supra-maximal exercise, although minor increases in blood bicarbonate were shown (Painelli, Silva 2014). Since the exercise protocol used by Painelli, Silva (2014) was highly acidotic and sensitive to detect performance improvements elicited by increased blood buffering capacity (Artioli et al. 2007; Tobias et al. 2013), these results have cast some doubt as to whether lactate is an effective buffering agent. One possible explanation for the lack of a positive effects with lactate could be related to the use of acute supplementation protocols since their alkalinising effects are transient, meaning that blood $\mathrm{pH}$ and bicarbonate return to baseline

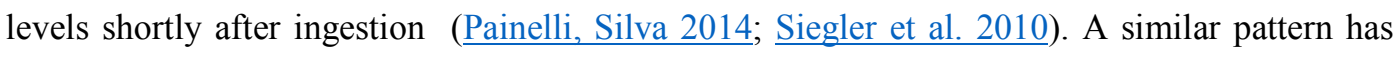
also been shown following acute sodium bicarbonate ingestion (Siegler, Midgley 2010). On the other hand, chronic sodium bicarbonate supplementation has been shown to result in prolonged metabolic alkalosis with positive performance effects lasting up to 48 hours after the cessation of supplementation (McNaughton et al. 1999; Tobias, Benatti 2013). Therefore, it is plausible that the ergogenic effects of calcium lactate could become more apparent if a chronic supplementation protocol, eliciting more sustained increases in blood bicarbonate, was employed.

In the present study, we investigated the effects of chronic lactate supplementation on blood bicarbonate, $\mathrm{pH}$ and subsequent exercise performance using an exercise protocol designed to induce a pronounced acidosis. In order to attest that our protocol was sensitive enough to 
111 detect the ergogenic effects of a buffering agent, chronic sodium bicarbonate supplementation

112 was used as a positive control. We hypothesised that chronic lactate supplementation could 113 induce a sufficiently large and sustained metabolic alkalosis capable of improving repeated 114 high-intensity exercise performance.

115

116

117

118

119

120

121

122

123

124

125

126

127

128

129

130

131

132

133

134

135

136

137

138

\section{METHODS}

\section{Participants}

Eighteen rugby $(n=11)$, judo $(n=2)$ and jiu-jitsu $(n=5)$ athletes actively training and competing at university level completed the study (age: $26 \pm 5$ years; body mass [BM]: $88.8 \pm$ $6.8 \mathrm{~kg}$; height: $1.78 \pm 0.07 \mathrm{~m}$; body fat: $18.6 \pm 6.2 \%$ ). Inclusion criteria were: male athletes aged 18 to 35 years engaged in sports requiring high levels of anaerobic metabolism of the upper limbs; minimum training experience of 2 years; minimum training volume of 6 hours per week. Exclusion criteria included the use of creatine and beta-alanine in the previous 3 and 6 months, respectively, the presence of any musculoskeletal disorder and any previous use of anabolic steroids. Participants were requested to maintain similar levels of physical activity and food intake throughout the duration of the study; compliance with these requests was verbally confirmed. Participants were informed about the risks and discomforts associated with participation and thereafter provided written consent. The study was approved by the Institutional Ethics Committee (29181114.0.0000.5391).

\section{Study Design}

A double-blind, placebo-controlled, crossover, counterbalanced study was conducted. Participants visited the laboratory on six separate occasions, separated by 2-7 days, to undertake 4 bouts of the upper-body Wingate anaerobic test. The first and second visits were performed to familiarise the participants with the protocol, while the third session was undertaken following no treatment (control). The remaining three sessions were undertaken following the acute ingestion of calcium lactate, sodium bicarbonate or placebo. The order of the treatments was 
chosen at random in a fully counterbalanced manner. To further confirm that the order of the tests did not influence performance, we compared overall total mechanical work (TMW) obtained in the experimental sessions between the three visits (see more details below). As expected, no significant differences were found (visit 1: $33462 \pm 5122 \mathrm{~J}$; visit 2: $33813 \pm 5371$ $\mathrm{J}$; visit 3: $33436 \pm 4928 \mathrm{~J} ; \mathrm{F}=0.70, p=0.50)$. All tests were performed during the same period of the day to account for circadian variation (Atkinson \& Reilly 1996).

The volunteers were instructed to arrive at the laboratory in a well fed and hydrated state, without having ingested any food in the $2 \mathrm{~h}$ preceding the tests. In order to minimise the influence of diet on performance, athletes were requested to maintain the same diet prior to all trials and this was confirmed by the analysis of all individual's $72 \mathrm{~h}$ food recall prior to each test. The participants were also informed to refrain from strenuous exercise and caffeine in the 24 hours preceding the experimental sessions. Compliance with these requests was verbally confirmed before each trial. Body fat was estimated by hydrostatic weighing measuring body volume density and calculating perceptual body fat using the equation proposed by Siri (1961).

Participants performed four bouts of the Wingate upper-body anaerobic test during every session. Blood samples were collected at rest (baseline), immediately after and 5 min after the fourth bout of the Wingate test. The efficacy of the blind procedure was verified during all trials; immediately after exercise, participants were asked to report which treatment they believed they had received, and to describe all perceived side effects.

\section{High-Intensity Intermittent Performance}

High-intensity intermittent exercise performance was assessed using 4 bouts of the upper-body Wingate Anaerobic Test, a protocol that has been previously used to assess the effects of metabolic induced alkalosis on performance in athletes (Artioli, Gualano 2007; Tobias, Benatti 2013). Athletes warmed up by performing arm-cranking with no resistance for 3 minutes, followed by 1 min rest prior to the first bout. Each bout of the Wingate Test began from a static start and lasted 30 seconds; the athletes were required to perform all-out armcranking at maximal velocity throughout the entire 30 seconds against a fixed load equivalent to 
$1674 \%$ BM. The volunteers were verbally encouraged during the exercise. The four bouts were 168 interspersed by 3-minute periods of active recovery, with no load, at a self-selected cadence. 169 The active recovery was chosen in order to avoid post-exertion vasovagal response between the 170 Wingate bouts; previous studies using similar exercise protocols have shown no performance 171 effects of active recovery (Franchini et al. 2003; Ouergui et al. 2014). The tests were performed 172 on a mechanically-braked upper body ergometer; wheel velocity was measured by a set of 24 173 sensors and power output was calculated automatically every second by computer software 174 (Ergometric 6.0, Cefise, Brazil). TMW was obtained and calculated for the overall test session. 175 In order to evaluate whether our intervention was more effective during the initial or final bouts 176 of the exercise test, TMW was also calculated for the initial (i.e., $1^{\text {st }}+2^{\text {nd }}$ ) and the final (i.e., $3^{\text {rd }}$ $177+4^{\text {th }}$ ) bouts. Performance decrement was measured as the percentage loss in mechanical work 178 from the $1^{\text {st }}$ to the $4^{\text {th }}$ bout. The coefficient of variation for TMW obtained in the testing sessions was $2.62 \pm 3.12 \%$.

180

\section{Supplementation protocol}

Participants underwent 5 days of chronic supplementation of either $500 \mathrm{mg} \cdot \mathrm{kg}^{-1} \cdot \mathrm{d}^{-1} \mathrm{BM}$ of calcium lactate ( $\mathrm{PhD}$ Innovation Expertise, Sao Paulo, Brazil), sodium bicarbonate (LabSynth, Sao Paulo, Brazil) or calcium carbonate (placebo; LabSynth, Sao Paulo, Brazil). The total daily dose was divided into 4 individual doses of $125 \mathrm{mg} \cdot \mathrm{kg}^{-1} \mathrm{BM}$ and all supplements were given in gelatin capsules identical in number, size and appearance. Participants were required to ingest their last dose within 4 hours before the performance assessment. In order to control adherence to the protocol, each individual dose was provided in a separate plastic bag identified with an adhesive tape. A supplementation log was given to the participants and they were asked to paste every label on the log sheet immediately after ingestion. All participants received $5 \%$ more individual doses than necessary without being informed, so adherence to supplementation could be further confirmed by the leftover capsules. 
Venous blood samples $(1 \mathrm{~mL})$ were collected at baseline, immediately after and 5

196

197

198

199

200

201

202

203

204

205

206

207

208

209

210

211

212

213

214

215

216

217

218

219

220

221

222

minutes after the last Wingate bout for the determination of blood $\mathrm{pH}$, bicarbonate, base excess and plasma lactate. Samples were taken from the antecubital vein using a heparinised syringe (BD A-Line $\mathrm{Ca}^{2+} \mathrm{LH} \sim 30$ I.U.) and immediately injected into an automatised blood gas analyser (Rapid Point 350®, Siemens, Germany) for $\mathrm{pH}$ and $\mathrm{PCO}_{2}$ determination. Blood bicarbonate and base excess were calculated according to the Henderson-Hasselbalch equation. For plasma lactate analysis, a small aliquot $(20 \mu \mathrm{L})$ of the sample was placed in a microtube containing the same volume of an ice-cold $2 \% \mathrm{NaF}$ solution and homogenised. The samples were then centrifuged at $2000 \mathrm{~g}$ for $5 \mathrm{~min}$ at $4^{\circ} \mathrm{C}$ to separate plasma from erythrocytes. Plasma was removed and stored at $-80^{\circ} \mathrm{C}$ until analysis. Plasma lactate was determined spectrophotometrically using an enzymatic-colorimetric method as supplied by a commercially available kit (Katal, Interteck, Sao Paulo, Brazil).

\section{Food intake assessment}

To control for intervening variables, food intake was assessed during the supplementation week of each experimental condition by means of three 24-h dietary recalls undertaken on separate days ( 1 weekend day and 2 consecutive weekdays preceding every test day), with the aid of a visual photo album of real-sized foods and portions. The 24-h dietary recall consisted of listing the foods and beverages consumed during the 24-h before the assessment. Nutritional supplements were also recorded. Energy and macronutrient intake were analysed with Virtual Nutri software (Sao Paulo, Brazil).

\section{Statistical Analysis}

Data are presented as mean \pm standard deviation. Mixed models (proc mixed, SAS 9.3) followed by single degree of freedom contrast analysis were used to examine changes in blood variables (plasma lactate, blood $\mathrm{pH}$, bicarbonate and base excess), with 'treatment' and 'time' as fixed factors and 'participants' as random factors. Absolute and relative $\Delta \mathrm{TMW}$ were calculated by subtracting control values from those obtained in each trial (i.e. calcium lactate, sodium 
223 bicarbonate and placebo). $\triangle \mathrm{TMW}$ was compared between treatments using repeated measures 224 ANOVA ('treatment' as a fixed factor) followed by Tukey's post-hoc test. Repeated measures 225 ANOVA followed by Tukey's post-hoc test were also used to compare the relative performance 226 decrement as well as food intake data between the experimental conditions. This same 227 procedure was employed to analyse the absolute change in TMW in the $1^{\text {st }}+2^{\text {nd }}$ and $3^{\text {rd }}+4^{\text {th }}$ 228 bouts. Effect sizes were calculated using Cohen's d. In addition, magnitude-based inference analysis was conducted on TMW based upon the recommendations of Batterham and Hopkins (2006) to detect small effects of practical relevance. The Fischer Exact Test was used for the rate of participants who correctly guessed their allocation in the trials. Statistical significance was accepted at $p \leq 0.05$.

\section{RESULTS}

235

\section{High-Intensity Intermittent Performance}

There was a main effect of 'treatment' on TMW $(F=3.40 ; p=0.02)$ with post hoc test indicating a significant difference between sodium bicarbonate and placebo $(\mathrm{p}=0.02 ; 95 \% \mathrm{CI}=$ 61 - 2043 J). ANOVA showed that sodium bicarbonate promoted a significantly higher absolute change in TMW versus control ( $\triangle \mathrm{TMW}$; Figure 1 , Panel A) than calcium lactate $(\mathrm{p}=$ $0.03 ; 95 \% \mathrm{CI}=-67-1827 \mathrm{~J} ; \mathrm{ES}=0.74)$ and placebo $(\mathrm{p}=0.01 ; 95 \% \mathrm{CI}=106-1999 \mathrm{~J} ; \mathrm{ES}=$ 0.99) whereas calcium lactate was not different from placebo $(\mathrm{p}=0.75 ; 95 \% \mathrm{CI}=-774-1119$ $\mathrm{J} ; \mathrm{ES}=0.1)$. There was no main effect of 'treatment' on TMW in the $1^{\text {st }}+2^{\text {nd }}$ bouts $(\mathrm{F}=0.99 ; p$ $244=0.38)$ (Figure 1, Panel B). However, a significant main effect of 'treatment' was shown in the $3^{\text {rd }}+4^{\text {th }}$ bouts $(\mathrm{F}=7.61 ; p=0.001)$ with sodium bicarbonate being superior to calcium lactate $(p$ $<0.01 ; 95 \% \mathrm{CI}=188-1194 \mathrm{~J} ; \mathrm{ES}=0.84)$ and placebo $(p<0.01 ; 95 \% \mathrm{CI}=192-1198 \mathrm{~J} ; \mathrm{ES}=$ 0.88). On the other hand, calcium lactate was not different from placebo $(p>0.01 ; 95 \% \mathrm{CI}=-$ 499 - $507 \mathrm{~J} ; \mathrm{ES}=0.05)($ Figure 1, Panel C). ANOVA also showed a main effect of 'treatment' on relative performance decrement $(\mathrm{F}=4.17 ; p=0.01)$, with sodium bicarbonate promoting a 
251

252

253

254

255

256

257

258

259

260

261

262

263

264

265

266

267

268

269

270

271

272

273

274

275

276

277

$8.72 \% ; p=0.02 ; 95 \% \mathrm{CI}=0.15-8.61 \%)$ and placebo $(-36.15 \pm 8.93 \% ; p=0.05 ; 95 \% \mathrm{CI}=-$ $1.95-6.50 \%)$.

Individual data analysis showed that 4 out of 18 participants improved TMW above the coefficient of variation with calcium lactate during the initial bouts $\left(1^{\text {st }}+2^{\text {nd }}\right)$, while only 3 and 2 improved with sodium bicarbonate and placebo, respectively (Figure 2, Panel A). However, 13 out of 18 improved TMW with sodium bicarbonate above the coefficient of variation during the final bouts $\left(3^{\text {rd }}+4^{\text {th }}\right)$, while only 8 improved with calcium lactate and placebo (Figure 2, Panel B). Furthermore, compared to control, magnitude-based inference analysis showed that sodium bicarbonate had a positive and possibly beneficial effect on TMW, while both calcium lactate and placebo only had trivial and unclear effects on performance (Table 1). When taking into account only the final bouts, both calcium lactate and placebo remained with a trivial and unclear effect on performance, while sodium bicarbonate had a positive and very likely beneficial effect on TMW.

\section{Blood Measures}

Blood variables are presented in Figure 3. The Mixed Model analysis showed a significant main effect of 'time' for blood $\mathrm{pH}(\mathrm{F}=713.88 ; p<0.0001)$, bicarbonate $(\mathrm{F}=$ 1157.73; $p<0.0001)$ and base excess $(\mathrm{F}=1113.64 ; p<0.0001)$, indicating that these variables significantly decreased from baseline to immediately post-exercise and 5 minutes post-exercise. Similarly, a significant main effect of 'time' for plasma lactate $(\mathrm{F}=1210.45 ; p<0.0001)$ was shown, indicating an increase from baseline to immediately post-exercise and 5 minutes postexercise.

There was a trend towards an effect of 'treatment' on blood bicarbonate $(\mathrm{F}=2.60 ; p=$ 0.06). No main effect of 'treatment' was found for blood $\mathrm{pH}(\mathrm{F}=0.46 ; p=0.71)$, base excess ( $\mathrm{F}$ $=1.61 ; p=0.19)$ and plasma lactate $(\mathrm{F}=1.72 ; p=0.17)$. However, the ANOVA showed that, at baseline, the absolute change in blood bicarbonate and base excess were significantly greater after sodium bicarbonate supplementation compared to calcium lactate or placebo $(p=0.0015$ 
1

2

3

4

278 and $\mathrm{p}=0.0013$ for blood bicarbonate, respectively; $\mathrm{p}=0.0018$ and $\mathrm{p}=0.0039$ for base excess.

279 See Table 2). No other significant differences in blood variables were shown (Table 2).

280

281

\section{Food Consumption Analysis}

Energy intake (sodium bicarbonate: $2006 \pm 556 \mathrm{kcal}$; calcium lactate: $1932 \pm 451 \mathrm{kcal}$; placebo: $1951 \pm 602 \mathrm{kcal} ; p=0.93$ ), carbohydrate (sodium bicarbonate: $46.6 \% \pm 8.9 \%$; calcium lactate: $46.6 \% \pm 10.8 \%$; placebo: $51.3 \% \pm 8.8 \% ; p=0.39$ ), lipid (sodium bicarbonate: $30.7 \% \pm$ 6.2\%; calcium lactate: $29.8 \% \pm 7.0 \%$; placebo: $27.2 \% \pm 6.6 \% ; p=0.30$ ), and protein (sodium bicarbonate: $22.7 \% \pm 6.7 \%$; calcium lactate, $21.5 \% \pm 6.8 \%$; placebo: $21.4 \% \pm 5.3 \% ; p=0.83$ ) did not significantly differ between the experimental conditions.

\section{Blinding Efficacy and Side Effects}

There was no apparent effect of correct supplement identification or self-reported sideeffects on TMW during either the initial $1^{\text {st }}+2^{\text {nd }}$ or final $3^{\text {rd }}+4^{\text {th }}$ bouts (Supplementary Figure 1 ). Eight out of 18 participants were able to correctly guess their supplement during the second trial, whereas 10 out of 18 correctly guessed their supplement in the first and third trials. There were no significant differences in the correct guessing rate between the trials (Fisher Exact Test: $p=0.83$ ). Two, 6 and 3 individuals who correctly guessed the supplement during calcium lactate, sodium bicarbonate and placebo improved during the $1^{\text {st }}+2^{\text {nd }}$ bouts, while 5,7 and 5 who correctly identified the ingested supplement did not improve TMW during these initial bouts. Six, 3 and 6 individuals who incorrectly guessed the supplement during calcium lactate, sodium bicarbonate and placebo improved during the $3^{\text {rd }}+4^{\text {th }}$ bouts; 6,1 and 4 individuals who incorrectly identified the ingested supplement did not improve during the final bouts. There were only 8 reports of side effects with calcium lactate (4 of these improved TMW during the initial bouts; 5 improved TMW during the final bouts), 8 with placebo (4 of these improved TMW during the initial bouts; 5 improved TMW during the final bouts) and 13 with sodium bicarbonate (6 of these improved TMW during the initial bouts; 11 improved TMW during the 
305 final bouts). Among the side effects, diarrhoea was the most frequent with 11 reports, followed

306 by eructation and stomach ache both with 6 reports.

307

308

DISCUSSION

309

310

311

312

313

314

315

316

317

318

319

320

321

322

323

324

To our knowledge, this is the first study investigating the effects of chronic (five days) calcium lactate supplementation on high-intensity intermittent performance as well as blood $\mathrm{pH}$ and bicarbonate. Since previous studies have shown that acute lactate supplementation induced a significant increase in extracellular buffering capacity (Morris, Shafer 2011; Painelli, Silva 2014; Van Montfoort, Van Dieren 2004), we hypothesized that our chronic strategy would produce greater increases in blood variables, and hence, in exercise performance.

In contrast to our initial hypothesis, we did not show any effect of lactate supplementation either on blood $\mathrm{pH}$ or blood bicarbonate. These results are somewhat surprising since our chronic protocol employed high calcium lactate doses $\left(500 \mathrm{mg} \cdot \mathrm{kg}^{-1} \cdot \mathrm{d}^{-1} \mathrm{BM}\right)$. However, because our positive control (i.e., sodium bicarbonate) did result in a significant increase in blood bicarbonate, we can rule out any explanation related to methodological errors. In agreement with our data, other studies have also shown little or no effect of lactate ingestion (Morris, Shafer 2011; Van Montfoort, Van Dieren 2004) or infusion (Miller et al. 2005) on blood $\mathrm{pH}$. On the other hand, studies have been more consistent in showing that lactate ingestion (Morris, Shafer 2011; Painelli, Silva 2014; Van Montfoort, Van Dieren 2004) or infusion (Miller, Lindinger 2005) increases blood bicarbonate. Although differences in the type of lactate salt ingested (calcium vs. sodium) may play a role on its alkalinizing effects $\left[\mathrm{Na}^{+}\right.$can increase strong ion difference thus having a greater impact on blood acid-base status (Miller, Lindinger 2005)], the lack of effect of lactate on blood bicarbonate in our study could not be entirely explained by the use of calcium instead of sodium lactate. In fact, calcium lactate has been shown to increase blood bicarbonate by $\sim 3 \mathrm{mM}$ (Morris, Shafer 2011), suggesting that other factors unrelated to the calcium form may explain our results. It is possible that the chronic protocol may have played some role as the alkalinizing effects of lactate might be more 
333 transient than sodium bicarbonate. Although this might be related to the fast lactate removal

334 from blood (Miller, Lindinger 2005), this explanation is still speculative and needs further examination.

The lack of changes in high-intensity intermittent performance in this study is likely a 337 reflection of the absence of changes in blood bicarbonate. Increases in circulating bicarbonate 338 resulted in a $1.7 \%$ increase in exercise capacity during a running-to-exhaustion lasting $\sim 80 \mathrm{~s}$ 339 (Van Montfoort, Van Dieren 2004) while Morris, Shafer (2011) demonstrated a 17\% 340 improvement in exercise capacity during a cycling-to-exhaustion test performed immediately 341 after $4 \times 1$-min bouts at 100\% of maximum power output. Contrarily, Painelli et al. (2014) 342 showed no changes in exercise performance during an upper-body repeated-bout Wingate test. 343 Using an exercise protocol very similar to that used by Painelli, Silva (2014), the current study 344 did not show any changes in total work or performance decrement with chronic lactate 345 supplementation. These discrepancies on performance outcomes may also be related to the 346 differences in exercise protocols. In this sense, time-to-exhaustion protocols usually do not have 347 either good external validity or good reliability (Currell \& Jeukendrup 2008). On the other hand, 348 the Wingate Test is known to have good reliability (Bar-Or 1987) and exhibits heavy reliance 349 on glycolytic metabolism (Lovell et al. 2013). Moreover, similar protocols using multiple bouts 350 of the Wingate Test have been associated with performance and success in a variety of sports 351 modalities (Franchini et al. 2011). The substantial fall in blood $\mathrm{pH}$ and bicarbonate observed 352 after the exercise protocol in the current investigation highlights its intense and acidotic nature. 353 As a matter of fact, previous studies have shown that our exercise protocol is sensitive to detect 354 the ergogenic effects of buffering agents, such as beta-alanine and sodium bicarbonate (Artioli, 355 Gualano 2007; Tobias, Benatti 2013), which was further confirmed in this study by the positive 356 effects of sodium bicarbonate on performance. This suggests that lactate supplementation is not 357 an effective buffering agent, at least if taken in its calcium form following a chronic protocol.

358 In contrast to lactate, chronic sodium bicarbonate supplementation has been widely 359 studied and employed as an extracellular buffer (Carr, Hopkins 2011). Some of the most 360 consistently demonstrated effects of sodium bicarbonate include increased blood $\mathrm{pH}$ and 
361 bicarbonate concentration. Since $\mathrm{H}^{+}$removal from muscle cells is driven, among other factors,

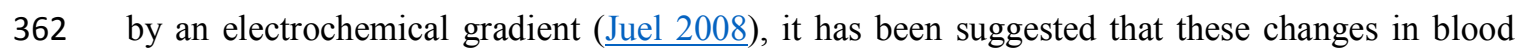
363 acid-base status promote greater efflux of $\mathrm{H}^{+}$and lactate from the working muscles (Raymer et 364 al. 2004). Consequently, there will be a reduced interference of $\mathrm{H}^{+}$with the contractile and 365 energy production processes inside muscle cells (Fitts 1994; Sahlin, Harris 1975), thereby 366 delaying fatigue onset. At baseline, chronic sodium bicarbonate supplementation successfully 367 increased blood bicarbonate and base excess, which may have attenuated the decline in 368 intramuscular $\mathrm{pH}$ during exercise. Such changes induced a significant improvement of $2.9 \%$ in 369 TMW, which was above the calculated coefficient of variation for the test. The efficacy of 370 sodium bicarbonate in the current study became even clearer in the final bouts, where one would 371 expect a higher degree of muscle acidosis, and hence, a greater opportunity of action for a 372 buffering agent. Therefore, our results agree with previous reports showing that chronic 373 bicarbonate supplementation is an effective strategy to enhance extracellular buffering capacity 374 (Mc Naughton \& Thompson 2001; McNaughton, Backx 1999), which contrasts with the 375 inability of a similar protocol using calcium lactate to induce the same effects. A recent study has suggested that a minimum increase of $5-6 \mathrm{mmol} \cdot \mathrm{L}^{-1}$ in blood bicarbonate is necessary for a potential ergogenic effect, while increases in excess of $6 \mathrm{mmol} \cdot \mathrm{L}^{-1}$ will almost certainly result in an ergogenic effect (Carr, Hopkins 2011). In the present study we employed a chronic supplementation protocol for both sodium bicarbonate and calcium lactate with the participants being required to ingest the last dose $4 \mathrm{~h}$ prior to attending to the laboratory. This period was intentionally chosen so any effect would be due to chronic supplementation rather than acute ingestion of the supplements. The mean absolute increase in blood bicarbonate promoted by sodium bicarbonate and calcium lactate were $2.5 \pm 2.0$ and -0.1 $384 \pm 2.3 \mathrm{mmol} \cdot \mathrm{L}^{-1}$, respectively. To our surprise, no effects of sodium bicarbonate on blood $\mathrm{pH}$ were observed, which contrasts with previous findings (McNaughton, Backx 1999). Despite the smaller increase in blood bicarbonate compared to the literature and the lack of effect on $\mathrm{pH}$, 387 only one participant did not respond to sodium bicarbonate supplementation (who also did not 388 report a $100 \%$ adherence to the supplementation protocol), suggesting that increased blood $\mathrm{pH}$ 
1

2

3

4

5

6

7

8

9

10

389 is not a prerequisite for an ergogenic effect with sodium bicarbonate provided that there is an

390 increase in blood bicarbonate. In fact, other investigations have already shown performance

The present study shows that chronic calcium lactate is not an effective supplement to improve blood buffering capacity and does not enhance high-intensity exercise performance; our results further confirm that chronic sodium bicarbonate supplementation is effective at both improving blood buffering capacity and exercise performance. In view of the conflicting data in the literature when an acute lactate ingestion protocol is used, the applicability of calcium lactate acutely ingested in a sporting context needs to be further examined. The use of a positive control such as sodium bicarbonate seems to be relevant to more precisely attest or refute its 


\section{ACKNOWLEDGEMENTS}

418

419 We wish to thank the Laboratório de Determinantes Energéticos de Desempenho 420 Esportivo (LADESP) for access to the ergometer used in this study and the volunteers for their 421 efforts. Luana F. de Oliveira, Kleiner Nemezio, Livia S. Gonçalves have been financially 422 supported by Coordenação de Aperfeiçoamento de Pessoal de Nível Superior (CAPES). Bryan 423 Saunders (150513/2015-1) has been financially supported by Conselho Nacional de 424 Desenvolvimento Científico e Tecnológico (CNPq). Vitor S. Painelli, Bruno Gualano and 425 Guilherme G. Artioli have been financially supported by Fundação de Amparo à Pesquisa do 426 Estado de São Paulo (FAPESP grants number: 2013/04806-0, 2013/14746-4, 2014/11948-8).

427

428 Conflict of interest: The authors declare that they have no conflict of interest.

429 


\section{REFERENCES}

431

432

Allen DG, Lamb GD, Westerblad H. Skeletal muscle fatigue: cellular mechanisms.

433 Physiological reviews. 2008: 88: 287-332.

434 Artioli GG, Gualano B, Coelho DF, Benatti FB, Gailey AW, Lancha AH, Jr. Does sodiumbicarbonate ingestion improve simulated judo performance? International journal of sport nutrition and exercise metabolism. 2007: 17: 206-217.

437 Atkinson G, Reilly T. Circadian variation in sports performance. Sports medicine. 1996: 21: 292-312.

439 Bar-Or O. The Wingate anaerobic test. An update on methodology, reliability and validity.

$440 \quad$ Sports medicine. 1987: 4: 381-394.

441 Batterham AM, Hopkins WG. Making meaningful inferences about magnitudes. International

442 journal of sports physiology and performance. 2006: 1: 50-57.

443 Boning D, Klarholz C, Himmelsbach B, Hutler M, Maassen N. Extracellular bicarbonate and

444 non-bicarbonate buffering against lactic acid during and after exercise. European journal of

445 applied physiology. 2007: 100: 457-467.

446 Brooks GA. The lactate shuttle during exercise and recovery. Medicine and science in sports

447 and exercise. 1986: 18: 360-368.

448 Carr AJ, Hopkins WG, Gore CJ. Effects of acute alkalosis and acidosis on performance: a meta449 analysis. Sports medicine. 2011: 41: 801-814.

450 Costill DL, Barnett A, Sharp R, Fink WJ, Katz A. Leg muscle pH following sprint running.

451 Medicine and science in sports and exercise. 1983: 15: 325-329.

452 Currell K, Jeukendrup AE. Validity, reliability and sensitivity of measures of sporting

453 performance. Sports medicine. 2008: 38: 297-316.

454 Donaldson SK, Hermansen L, Bolles L. Differential, direct effects of $\mathrm{H}+$ on Ca2+-activated

455 force of skinned fibers from the soleus, cardiac and adductor magnus muscles of rabbits.

456 Pflugers Archiv : European journal of physiology. 1978: 376: 55-65.

457 Fabiato A, Fabiato F. Effects of pH on the myofilaments and the sarcoplasmic reticulum of 458 skinned cells from cardiace and skeletal muscles. The Journal of physiology. 1978: 276: 233459255.

460 Fahey TD, Larsen JD, Brooks GA, Colvin W, Henderson S, Lary D. The effects of ingesting 461 polylactate or glucose polymer drinks during prolonged exercise. International journal of sport 462 nutrition. 1991: 1: 249-256.

463 Fitts RH. Cellular mechanisms of muscle fatigue. Physiological reviews. 1994: 74: 49-94. 
464 Franchini E, Del Vecchio FB, Matsushigue KA, Artioli GG. Physiological profiles of elite judo

465 athletes. Sports medicine. 2011: 41: 147-166.

466 Franchini E, Yuri Takito M, Yuzo Nakamura F, Ayumi Matsushigue K, Peduti Dal'Molin Kiss

467 MA. Effects of recovery type after a judo combat on blood lactate removal and on performance

468 in an intermittent anaerobic task. The Journal of sports medicine and physical fitness. 2003: 43:

$469 \quad 424-431$.

470 Heller MD, Kern F, Jr. Absorption of lactic acid from an isolated intestinal segment in the intact

471 rat. Proceedings of the Society for Experimental Biology and Medicine Society for Experimental

472 Biology and Medicine. 1968: 127: 1103-1106.

473 Hostetler KY, Williams HR, Shreeve WW, Landau BR. Conversion of specifically 14 C-labeled

474 lactate and pyruvate to glucose in man. The Journal of biological chemistry. 1969: 244: 2075-

4752077.

476 Jacobs RA, Meinild AK, Nordsborg NB, Lundby C. Lactate oxidation in human skeletal muscle

477 mitochondria. Am J Physiol Endocrinol Metab. 2013: 304: E686-694.

478 Juel C. Lactate/proton co-transport in skeletal muscle: regulation and importance for $\mathrm{pH}$

479 homeostasis. Acta physiologica Scandinavica. 1996: 156: 369-374.

480 Juel C. Regulation of $\mathrm{pH}$ in human skeletal muscle: adaptations to physical activity. Acta

481 physiologica. 2008: 193: 17-24.

482 Lancha Junior AH, Painelli VP, Saunders B, Artioli GG. Nutritional Strategies to Modulate

483 Intracellular and Extracellular Buffering Capacity During High-Intensity Exercise. Sports

484 medicine. 2015: 45 Suppl 1: 71-81.

485 Lovell D, Kerr A, Wiegand A, Solomon C, Harvey L, McLellan C. The contribution of energy

486 systems during the upper body Wingate anaerobic test. Applied physiology, nutrition, and

487 metabolism $=$ Physiologie appliquee, nutrition et metabolisme. 2013: 38: 216-219.

488 Mc Naughton L, Thompson D. Acute versus chronic sodium bicarbonate ingestion and

489 anaerobic work and power output. The Journal of sports medicine and physical fitness. 2001:

$490 \quad$ 41: 456-462.

491 McNaughton L, Backx K, Palmer G, Strange N. Effects of chronic bicarbonate ingestion on the

492 performance of high-intensity work. European journal of applied physiology and occupational

493 physiology. 1999: 80: 333-336.

494 Miller BF, Lindinger MI, Fattor JA, Jacobs KA, Leblanc PJ, Duong M, Heigenhauser GJ,

495 Brooks GA. Hematological and acid-base changes in men during prolonged exercise with and

496 without sodium-lactate infusion. Journal of applied physiology. 2005: 98: 856-865.

497 Morris DM, Shafer RS, Fairbrother KR, Woodall MW. Effects of lactate consumption on blood

498 bicarbonate levels and performance during high-intensity exercise. International journal of

499 sport nutrition and exercise metabolism. 2011: 21: 311-317. 
500 Ouergui I, Hammouda O, Chtourou H, Gmada N, Franchini E. Effects of recovery type after a

501 kickboxing match on blood lactate and performance in anaerobic tests. Asian J Sports Med.

502 2014: 5: 99-107.

503 Painelli VS, Saunders B, Sale C, Harris RC, Solis MY, Roschel H, Gualano B, Artioli GG, 504 Lancha AH, Jr. Influence of training status on high-intensity intermittent performance in 505 response to beta-alanine supplementation. Amino acids. 2014: 46: 1207-1215.

506 Painelli VS, Silva RP, de Oliveira OM, Jr., de Oliveira LF, Benatti FB, Rabelo T, Guilherme JP, 507 Lancha AH, Jr., Artioli GG. The effects of two different doses of calcium lactate on blood pH, 508 bicarbonate, and repeated high-intensity exercise performance. International journal of sport 509 nutrition and exercise metabolism. 2014: 24: 286-295.

510 Peart DJ, Siegler JC, Vince RV. Practical recommendations for coaches and athletes: a meta-

511 analysis of sodium bicarbonate use for athletic performance. Journal of strength and

512 conditioning research / National Strength \& Conditioning Association. 2012: 26: 1975-1983.

513 Raymer GH, Marsh GD, Kowalchuk JM, Thompson RT. Metabolic effects of induced alkalosis

514 during progressive forearm exercise to fatigue. Journal of applied physiology. 2004: 96: 2050-

5152056.

516 Sahlin K, Harris RC, Hultman E. Creatine kinase equilibrium and lactate content compared with 517 muscle pH in tissue samples obtained after isometric exercise. The Biochemical journal. 1975:

518 152: 173-180.

519 Siegler JC, Midgley AW, Polman RC, Lever R. Effects of various sodium bicarbonate loading 520 protocols on the time-dependent extracellular buffering profile. Journal of strength and 521 conditioning research / National Strength \& Conditioning Association. 2010: 24: 2551-2557.

522 Siri WE. Body composition from fluid spaces and density: analysis of methods. In: Brozek J, 523 Henschel A, eds. Techiques for measuring body composition. Washington: National Academy 524 os Science, 1961:223-244.

525 Tobias G, Benatti FB, Painelli VS, Roschel H, Gualano B, Sale C, Harris RC, Lancha AH, Jr., 526 Artioli GG. Additive effects of beta-alanine and sodium bicarbonate on upper-body intermittent 527 performance. Amino acids. 2013: 45: 309-317.

528 Van Montfoort MC, Van Dieren L, Hopkins WG, Shearman JP. Effects of ingestion of 529 bicarbonate, citrate, lactate, and chloride on sprint running. Medicine and science in sports and 530 exercise. 2004: 36: 1239-1243. 
535

536

537 Figure 1. Total work. Panel A: Absolute change in total work ( $\Delta \mathrm{TMW})$ after sodium 538

539

540

541

542

543

544

545

546

547

548

549

550

551

552

553

554

\section{LEGENDS FIGURES} bicarbonate (SB), calcium lactate $(\mathrm{CL})$ or placebo (PL) supplementation compared to control; Panel B: Absolute change in TMW after SB, CL or PL in the initial bouts $\left(1^{\text {st }}+2^{\text {nd }}\right)$; Panel C: Absolute change in TMW after SB, CL or PL in the final bouts $\left(3^{\text {rd }}+4^{\text {th }}\right)$. Legend: the symbol * refers to a significant difference (at $\mathrm{p}<0.05$ ) compared to the other experimental conditions.

Figure 2. Individual analysis. Panel A: Individual analysis of the relative change in total work ( $\triangle \mathrm{TMW}$ ) during the initial bouts $\left(1^{\mathrm{st}}+2^{\text {nd }}\right)$ compared to the control session; Panel B: Individual analysis of the relative change in TMW during the final bouts $\left(3^{\text {rd }}+4^{\text {th }}\right)$ compared to the control session. The dashed line represents the calculated variation of the exercise test.

Figure 3. Blood analysis. Chronic effects of sodium bicarbonate (SB), calcium lactate (calcium lactate) or placebo (PL) supplementation on blood levels of $\mathrm{pH}$, bicarbonate, base excess and plasma lactate at baseline (BASE), immediately after the Wingate test (POST) and 5 minutes after the Wingate test (5-MIN). Legend: the symbol ${ }^{\#}$ refers to a significant difference (at $p<$ 0.05 ) compared BASE; the symbol ${ }^{\&}$ refers to a significant difference (at $p<0.05$ ) compared to POST; the symbol * refers to a significant difference (at $p<0.05$ ) compared to the other conditions within the same moment. 
A

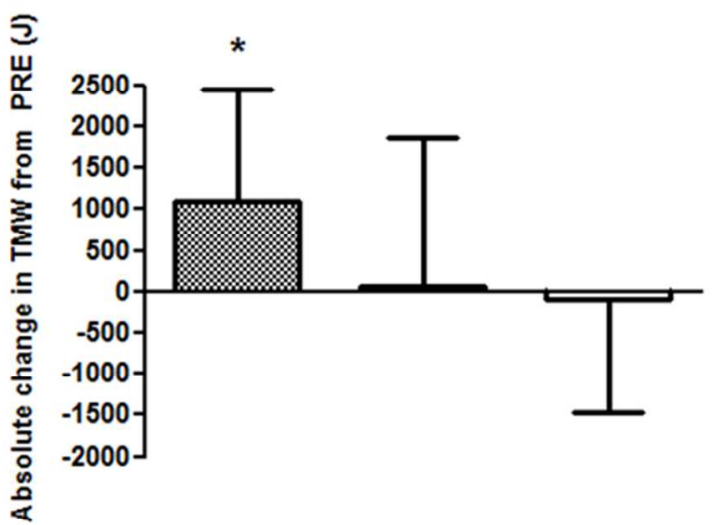

B

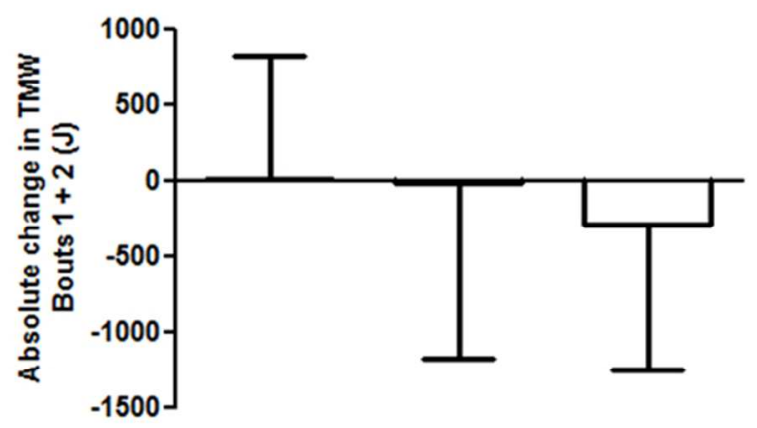

C

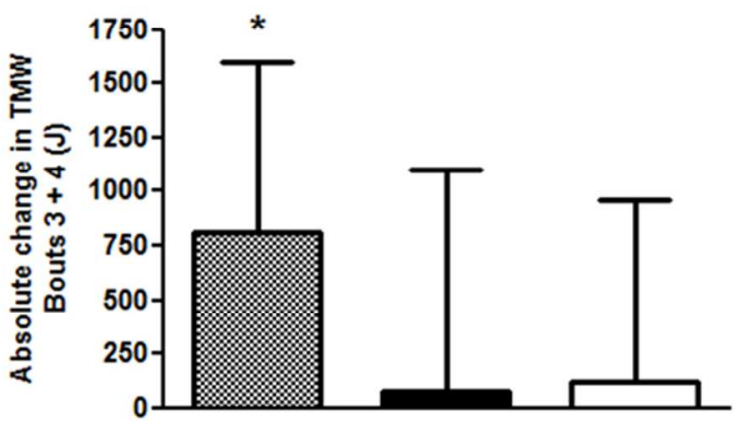

$190 \times 254 \mathrm{~mm}(96 \times 96 \mathrm{DPI})$
归 SB

CL $\square$ PL 

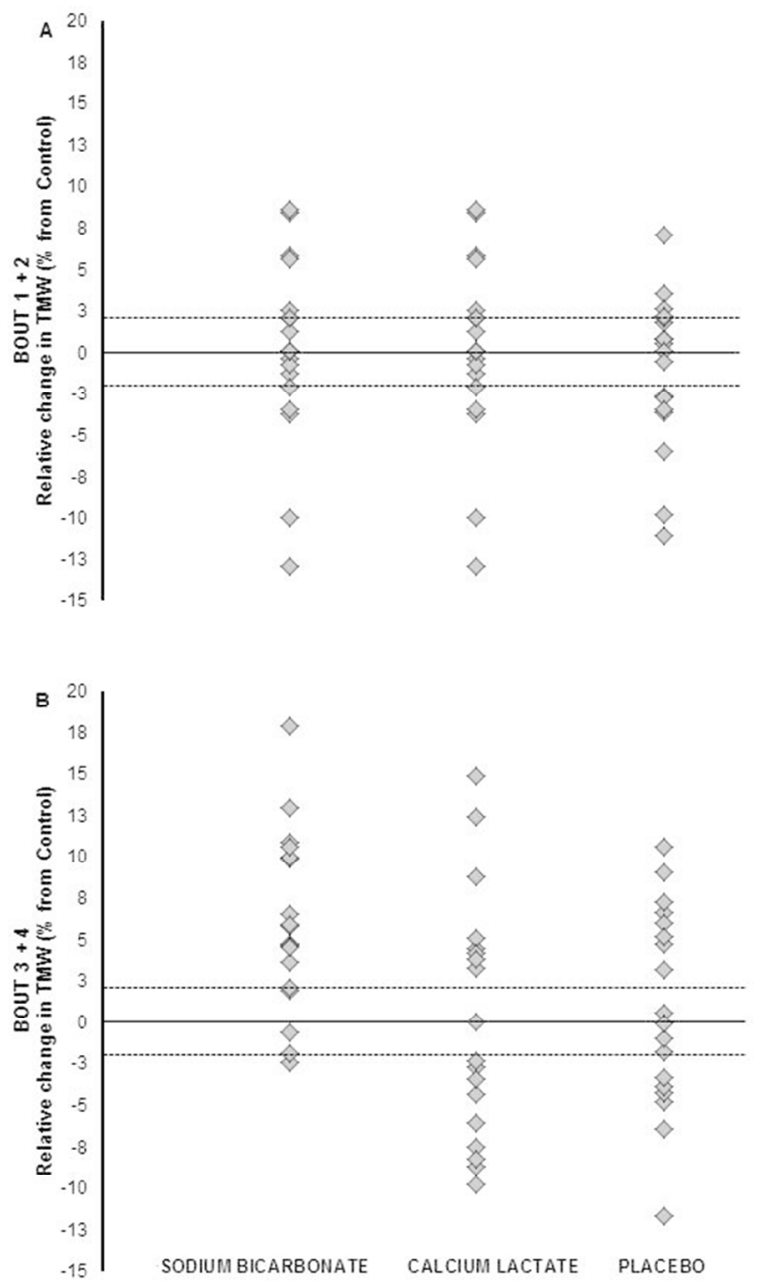

$190 \times 275 \mathrm{~mm}(96 \times 96 \mathrm{DPI})$ 
1

2

3

4

5

6

7

8

9

10

11

12

13

14

15

16

17

18

19

20

21

22

23

24

25

26

27

28

29

30

31

32

33

34

35

36

37

38

39

40

41

42

43

44

45

46

47

48

49

50

51

52

53

54

55

56

57

58

59

60
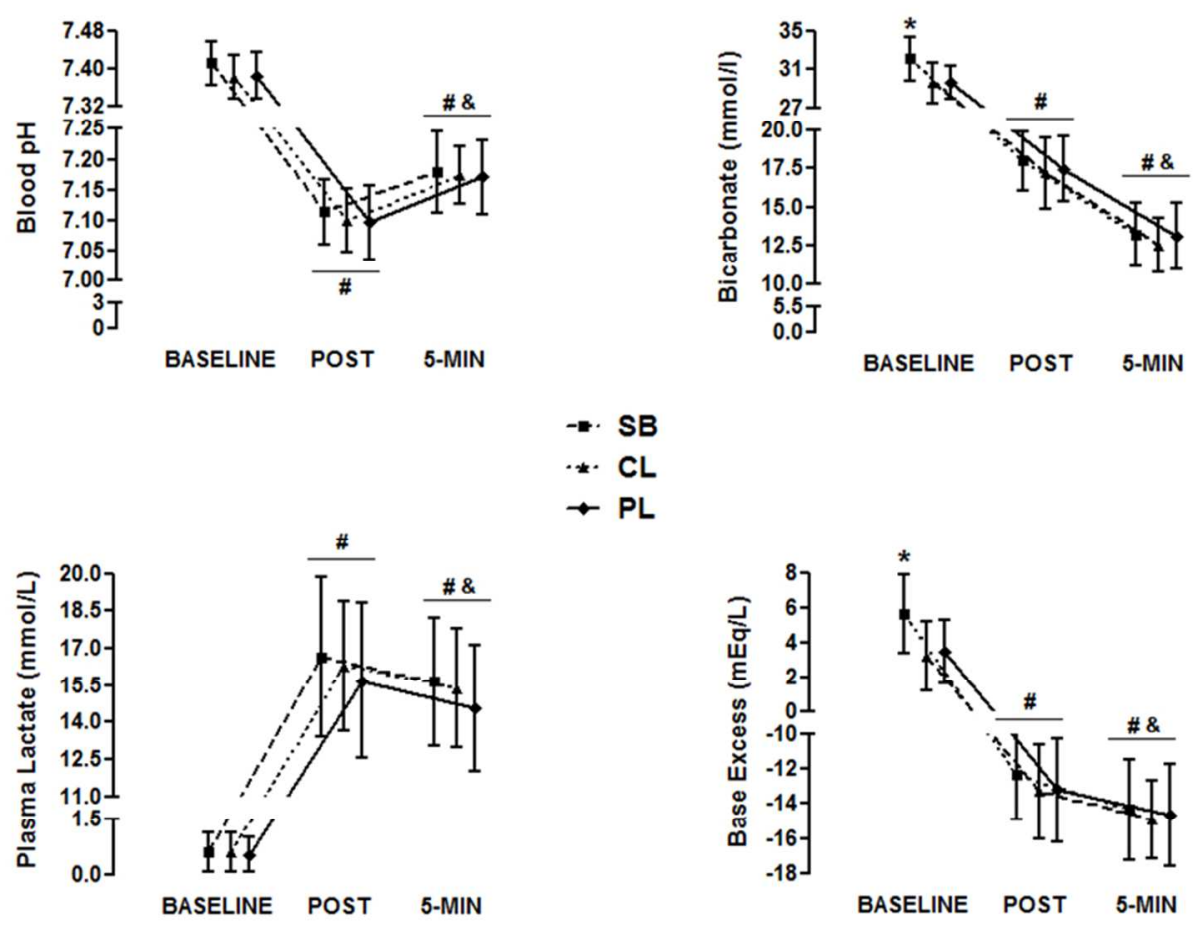

$254 \times 190 \mathrm{~mm}(96 \times 96 \mathrm{DPI})$ 
TABLE 1. ${ }^{1}$

\begin{tabular}{|c|c|c|c|c|}
\hline & $\begin{array}{l}\text { Difference } \\
(\%)\end{array}$ & $\begin{array}{c}\text { Chances of } \\
\text { treatment being } \\
\text { positive (\%) }\end{array}$ & $\begin{array}{c}\text { Chances of } \\
\text { treatment being } \\
\text { trivial (\%) }\end{array}$ & $\begin{array}{c}\text { Chances of } \\
\text { treatment being } \\
\text { negative }(\%) \\
\end{array}$ \\
\hline \multicolumn{5}{|c|}{ Total Mechanical Work } \\
\hline SB vs. CON & +2.86 & 64 & 36 & 0 \\
\hline CL vs. CON & +0.13 & 0 & 100 & 0 \\
\hline PL vs. CON & -0.02 & 0 & 99 & 1 \\
\hline SB vs. CL & +2.16 & 43 & 57 & 0 \\
\hline SB vs. PL & +2.64 & 57 & 43 & 0 \\
\hline CL vs. PL & -0.004 & 0 & 100 & 0 \\
\hline \multicolumn{5}{|c|}{$\begin{array}{l}\text { Total Mechanical Work } \\
\text { (Bouts 1+2) }\end{array}$} \\
\hline SB vs. CON & +0.13 & 0 & 99 & 0 \\
\hline CL vs. CON & +0.12 & 2 & 95 & 3 \\
\hline PL vs. CON & -1.01 & 0 & 85 & 15 \\
\hline SB vs. CL & +0.19 & 1 & 98 & 1 \\
\hline SB vs. PL & +1.31 & 17 & 83 & 0 \\
\hline CL vs. PL & +0.96 & 15 & 85 & 0 \\
\hline \multicolumn{5}{|c|}{$\begin{array}{l}\text { Total Mechanical Work } \\
\text { (Bouts 3+4) }\end{array}$} \\
\hline SB vs. CON & +5.93 & 96 & 4 & 0 \\
\hline CL vs. CON & +0.21 & 1 & 99 & 0 \\
\hline PL vs. CON & +0.87 & 6 & 93 & 1 \\
\hline SB vs. CL & +5.40 & 83 & 17 & 0 \\
\hline SB vs. PL & +5.22 & 86 & 14 & 0 \\
\hline CL vs. PL & -0.20 & 49 & 2 & 49 \\
\hline
\end{tabular}

${ }^{1}$ Table 1. Magnitude-based inferences for total mechanical work across conditions.

Legend: $\mathrm{SB}=$ sodium bicarbonate; $\mathrm{CL}=$ calcium lactate; $\mathrm{PL}=$ placebo $\mathrm{CON}=$ control session. 
TABLE 2. ${ }^{1}$

\begin{tabular}{lccc}
\hline & Baseline & $\begin{array}{c}\text { Immediately post- } \\
\text { exercise }\end{array}$ & $\begin{array}{c}\mathbf{5} \text { minutes post- } \\
\text { exercise }\end{array}$ \\
\hline $\mathbf{p H}$ & & & \\
Sodium Bicarbonate & $+0.035 \pm 0.048$ & $+0.033 \pm 0.046$ & $+0.026 \pm 0.065$ \\
Calcium Lactate & $+0.009 \pm 0.029$ & $+0.006 \pm 0.046$ & $+0.004 \pm 0.053$ \\
Placebo & $+0.019 \pm 0.038$ & $+0.016 \pm 0.044$ & $+0.013 \pm 0.039$ \\
Bicarbonate (mmol· $\mathbf{L}^{-\mathbf{1}}$ ) & & & \\
Sodium Bicarbonate & $+2.5 \pm 2.0^{*}$ & $+1.7 \pm 2.1$ & $+1.1 \pm 1.7$ \\
Calcium Lactate & $-0.1 \pm 2.3$ & $+0.6 \pm 2.3$ & $-0.66 \pm 2.4$ \\
Placebo & $-0.3 \pm 1.7$ & $+1.2 \pm 1.3$ & $+0.25 \pm 2.7$ \\
Base excess (mEq. $\left.\mathbf{L}^{-\mathbf{1}}\right)$ & & & $+1.5 \pm 2.7$ \\
Sodium Bicarbonate & $+2.7 \pm 2.1^{*}$ & $+2.2 \pm 2.6$ & $-0.4 \pm 2.9$ \\
Calcium Lactate & $+0.1 \pm 1.6$ & $+0.6 \pm 2.4$ & $+0.5 \pm 2.9$ \\
Placebo & $+0.1 \pm 1.6$ & $+1.3 \pm 1.9$ & \\
Lactate $\left(\mathbf{m m o l} \cdot \mathbf{L}^{-1}\right.$ ) & & & $+1.9 \pm 3.4$ \\
Sodium Bicarbonate & $+0.3 \pm 0.5$ & $+1.7 \pm 3.6$ & $+1.2 \pm 2.8$ \\
Calcium Lactate & $+0.2 \pm 0.5$ & $+1.4 \pm 3.9$ & $+0.8 \pm 3.6$ \\
Placebo & $+0.1 \pm 0.4$ & $+0.8 \pm 4.1$ & \\
\hline
\end{tabular}

\footnotetext{
${ }^{1}$ Table 2. Absolute changes in blood pH, bicarbonate, base excess and lactate from control session across the moments.

Legend: * means a significant $(\mathrm{p}<0.05)$ difference from the other conditions at the same moment.
} 

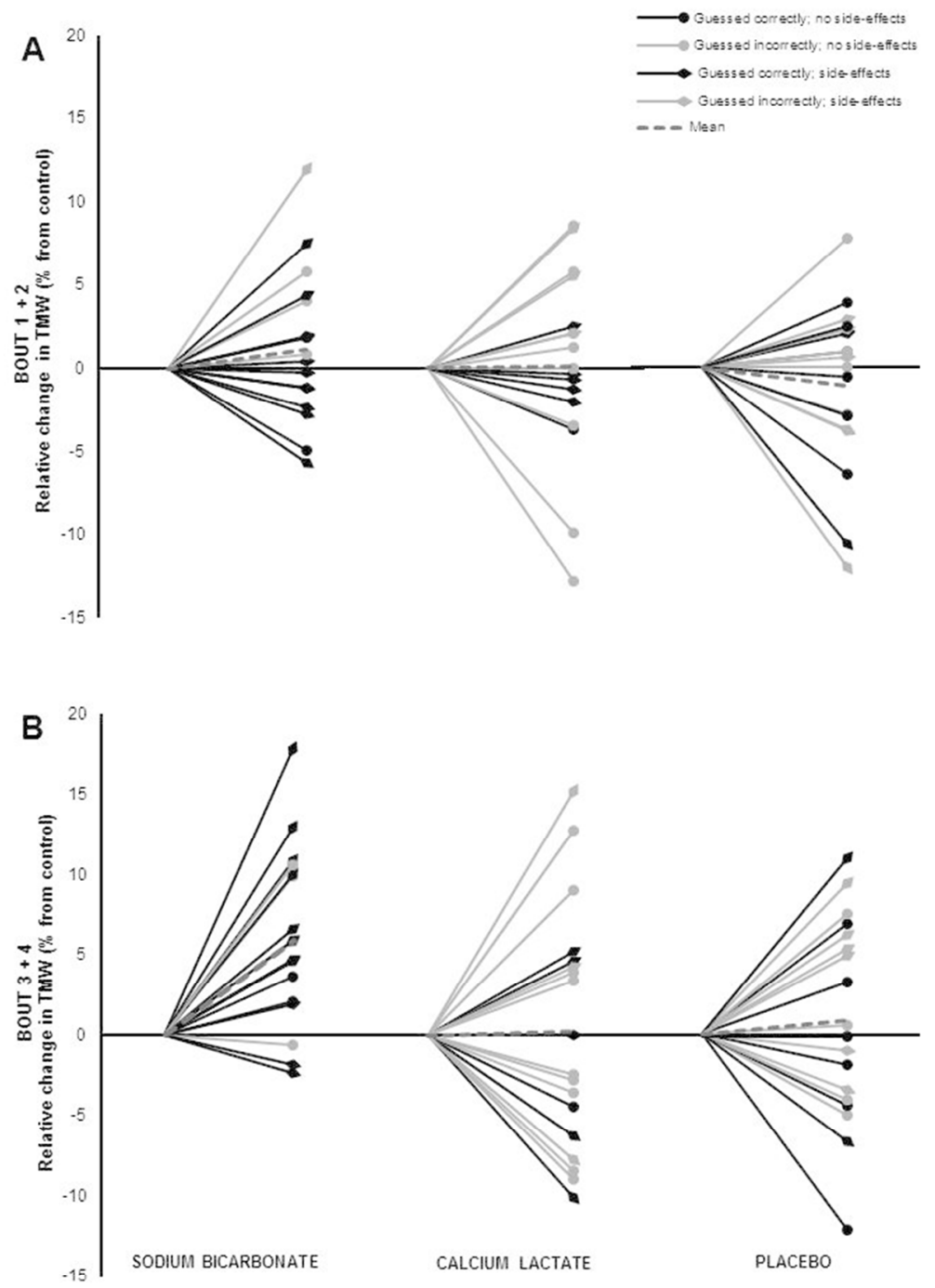

$190 \times 275 \mathrm{~mm}(96 \times 96 \mathrm{DPI})$ 
1

2

3

4

5

6

7

8

9

10

11

12

13

14

15

16

17

18

19

20

21

22

23

24

25

26

27

28

29

30

31

32

33

34

35

36

37

38

39

40

41

42

43

44

45

46

47

48

49

50

51

52

53

54

55

56

57

58

59

60

1 Supplementary Figure 1

2

3 Figure 1. Individual analysis side effects and blinding. Panel A: Side effects, blinding and 4 individual relative change in total work ( $\triangle \mathrm{TMW}$ ) compared to control session during the initial 5 bouts $\left(1^{\text {st }}+2^{\text {nd }}\right)$; Panel $B$ : Side effects, blinding and individual relative change in TMW 6 compared to control session during the final bouts $\left(3^{\text {rd }}+4^{\text {th }}\right)$. Legend: Individuals in black lines 7 correctly guessed the ingested supplement; individuals in gray lines incorrectly guessed the 8 ingested supplement; the dashed line refers to the mean relative change in TMW with the 9 treatment; individuals in diamond had side effects; individuals in circle did not report any side

10 effects. Overall, these data suggest no apparent effect of either correctly guessing the allocation 11 or self-reported side effects upon exercise performance. 